\title{
Knowledge Levels of Medical Students Related to Airway Management in Patients with Maxillofacial Trauma
}

\author{
Omer Ekici \\ Department of Oral and Maxillofacial Surgery, Faculty of Dentistry, Afyonkarahisar Health Sciences University, Afyonkarahisar, Turkey. \\ Correspondence Author: Omer Ekici \\ E-mail: dromerekici@hotmail.com \\ Received: 03.03.2021 Accepted: 25.07.2021
}

\begin{abstract}
Objective: Airway management in maxillofacial injuries is quite complex and involves many difficulties. The aim of this study is to evaluate the knowledge level of medical faculty students about airway management in maxillofacial injuries.

Methods: This cross-sectional study was conducted on fifth and sixth-grade students of the Faculty of Medicine, Afyonkarahisar Health Sciences University. After the literature review, a questionnaire was prepared to measure the knowledge level of the students about airway management in maxillofacial trauma. Two hundred eighty students participated in the study.

Results: Thirty percent of the students stated that they performed laryngeal mask airway, $61.1 \%$ orotracheal intubation, and $17.8 \%$ nasoendotracheal intubation. Thirty-four point forty-four percent of the students stated that they did not do any of these applications. Only $52.2 \%$ of the students stated that they used a traditional laryngoscope with Macintosh blades. While $81.1 \%$ of the students stated that they did not intubate at all in a patient with maxillofacial trauma, and $74.4 \%$ thought that a patient with maxillofacial trauma did not have the education and skills to perform intubation comfortably.
\end{abstract}

Conclusion: Results of the study reveal that students' knowledge and experience in airway management in emergencies such as maxillofacial trauma were insufficient. This deficiency was especially about the tools and methods used to provide airway patency.

Keywords: Maxillofacial trauma, airway management, emergency aid, medical students.

\section{INTRODUCTION}

There are severe difficulties for the doctors in patients with maxillofacial trauma, as airway management in these patients can be complicated due to damage to this region. The first difficulty is to safeguard the airway for efficient breathing. The physician should consider those factors when planning to ensure the safety of the airway: a) the severity of the wound and its impact on the airways; b) potential problems with mask breathing or endotracheal intubation; c) potential damage to the cervical spine; d) risk of aspiration of stomach contents; e) severe bleeding that obstructs the vision of the airways and can cause circulatory disturbances; and $(f)$ the form of maxilla-mandibular fixation (MMF) to be carried out at the end of the surgery (1).

There are six particular conditions related to maxillofacial trauma that could be negatively impacting the airway, according to Hutchison et al.(2): a)The nasopharyngeal airway can be obstructed by post-inferior displacement of a broken maxilla parallel to the inclined plane of the base of the skull; b)Bilateral anterior mandible fracture can cause the tongue to slip posteriorly in the supine patient and obstruct the oropharynx; c)Foreign bodies such as dentures and shrapnel, as well as fractured teeth, bone fragments, vomiting, blood, and secretions, may block the airway anywhere in the oropharynx and larynx; d)Bleeding from various vessels in open wounds or serious nasal bleeding can also lead to obstruction of the airways; e)Soft tissue swelling and edema caused by head and neck trauma can cause airway collapse; f)Larynx and trachea injuries could increase the risk of cervical airway obstruction by causing tissues such as epiglottis and vocal cords to swell and displace.

Airway care and cervical spine immobilization and are the highest priority for managing patients with life-threatening injuries, according to Advanced Trauma Life Support(ATLS) suggestions (3). Airway loss can be fatal and more quickly than the loss of breathing capacity or the initiation of circulatory issues. Therefore, life-saving procedures should start with airway management as necessary (4). In particular, the most prevalent crucial care mistakes that contribute to the death of trauma patients are involved in airway and respiratory care(5).Morbidity and mortality are frequently the results 
of critical care faults in in-hospital trauma patients, with airway management arethe most prevalent. Gruen et al.(6) investigated the reason of the death of 2594 trauma patients and found that $16 \%$ of inpatient deaths were due to the inability to be intubated or safeguard the airway.

Managing the airway in emergency conditions is an added hassle because the time to complete the mission is limited and the patient's health can get worse rapidly. The performance of emergency intubation is correlated with very high complication rates, which can overlap $20 \%(7,8)$. These raised rates are attributed to multiple causes, such as frequent intubation enterprises, the requirement for immediate laryngoscopy without muscle relief, and the operator's inexperience. Hypoxemia, aspiration, esophageal intubation, increases in heart rate, cardiac arrhythmias, and cardiac arrest are the major complications that may occur (1). Care for acute trauma patients in emergencies, is usually ensured by inexperienced people (9).In a multi-center study of 8937 intubations in the emergency room, Walls et al. (10) found that anesthesiologists conducted only $3 \%$ of intubations, while the other $97 \%$ were performed by emergency physicians $(87 \%)$ and other specialties (10\%). Unsuccessful attempts at endotracheal intubation by inexperienced people may cause a rapid deterioration in the patient's condition. To improve the clinical outcomes of patients with maxillofacial trauma, it is critical that the personnel managing the airways of such patients be trained and experienced. There is no study in the literature that investigates the knowledge levels of medical faculty students, who will be doctors of the future, about airway management in trauma patients. The purpose of this study is to assess the knowledge level of medical faculty students about airway management in maxillofacial injuries.

\section{METHODS}

This cross-sectional study was carried out on the students of Afyonkarahisar Health Sciences University Faculty of Medicine. The study was approved by the Clinical Studies Ethics Committee of Afyonkarahisar Health Sciences University (2021/1-26) and was conducted in accordance with the principles of the Helsinki Declaration. A total of 280 students, 135 from the 5th-class and 145 from the 6th-class, were included in the study. After the literature review, a questionnaire form was designed to measure the knowledge level of students about airway management in maxillofacial trauma.

The questionnaire form consisted of two or multiplechoice questions aiming to measure students' knowledge and experience, apart from demographic information such as age and gender. The first three questions consisted of multiple options and students were asked to select one or more options. 25 questions in the questionnaire consisted of statements containing false or correct information about airway management in maxillofacial injury, and students were asked to mark one of the "true" or "false" options for each statement. Correct answers were scored as '1 point' and the total scores of the students ranged from 0-25 points. The five questions of the survey were about the experience of getting to know and using the tools used in airline management. Survey questions in terms of content were checked by an emergency medicine physician. The validity and reliability of the questionnaire were verified with a pretest method in a group of 15 students. The questionnaire sample was sent to the students by e-mail.

\subsection{Statistical Analysis}

Survey data were analyzed Statistical Package for Social Sciences (SPSS) for Windows software, version 20.0 (SPSS Inc., Chicago, IL, USA). Descriptive statistics was given using the number and percentage. The compatibility of variables with normal distribution was reviewed by histogram graphics and Kolmogorov-Smirnov tests. When comparing the two groups, the independent samples $t$-test was used in evaluating parametric variables, and the Mann-Whitney $U$ test was used in evaluating nonparametric variables. The confidence interval was set to $95 \%$ and $p<0.05$ was considered statistically significant.

\section{RESULTS}

The questionnaire was answered by a total of 180 students, 124 from the 5th-class and 56 from the 6th-class of the medical faculty (response rate 64.28\%). Forty-seven point eight percent of the participants were male ( 86 student) and $52.2 \%$ were female(94 students). The minimum age was 22 , the maximum age was 30 (the mean age was 25.61).

The questionnaire asked what the most important priority is in life-threatening injuries according to the ATLS recommendations (3). Sixteen point seven percent of the participants gave the correct answer as airway management and cervical spine immobilization. The answers of the participants regarding the factors that make airway safety difficult in patients with maxillofacial trauma are given in figure 1. Half of the participants correctly marked all of these factors that make airway management difficult in patients with maxillofacial trauma. As hemostasis methods that can be applied in maxillofacial traumas; direct pressure (57.77\%), balloon packings (50\%), surgical ligation of vessels (41.11\%), sutures and staples (33.33\%), and intraarterial embolization $(17.77 \%)$ were stated by the participants. Only $8.8 \%$ of the participants stated all hemostasis methods in maxillofacial bleedings correctly.

Table 1 showed the percentage of correct answers given by the participants to the statements containing incorrect or correct information about airway management in maxillofacial

injuries. While the highest response rate (88.9\%) would be to "It should be assumed that the stomach of the patient with maxillofacial trauma is completely filled", the lowest response rate $(27.8 \%)$ would be "Fiber-optic intubation or video laryngoscope is superior in that it works without being affected by blood, vomit and secretions in the airway of the trauma patient ". The response percentage of 9 out 
of 25 statements in this category remained below $50 \%$, and most of them were related to the tools and methods used in airway management in maxillofacial injuries.

Table 2 shows the distribution of the average scores obtained by the participants according to their gender and school class. Accordingly, it was observed that the mean scores of women were significantly higher than men $(p<0.05)$. In addition, the mean scores of the 5 th-class students were found to be significantly higher than the 6 th-class students $(p<0.001)$. It was observed that the average score of all participants was 15.38 (in the range of 0-25 points). The distribution of the scores obtained by the students is given in figure 2. Here, too, it is seen that student scores are predominantly between 12 and 19 points.

Participants' application of methods to provide airway patency in emergency states is given in figure 3. Accordingly, $30 \%$ of the students stated that they performed laryngeal mask airway (LMA), $61.1 \%$ orotracheal intubation and $17.8 \%$ nasoendotracheal intubation. Thirty-four point forty four percent of the students stated that they did not do any of these applications. The laryngoscope usage situations of the students were shown in figure 4 . Accordingly, more than half of the students (\%52.2) stated that they used traditional laryngoscopes, and one-third stated that they used video laryngoscopes. Eighteen point nine percent of the students stated that they performed intubation in a patient with maxillofacial trauma. Only $25.6 \%$ of the students stated that they thought they had the education and skills to perform intubation in a patient with maxillofacial trauma. In an unconscious patient with maxillofacial trauma, the practices in which students consider themselves competent in airway management are given in figure 5. Accordingly, applying a face mask (\%73.3) and oral airway placement(\%67.8) were the two applications that students could do most. Besides, $\% 41.1$ of the students stated that they could perform orotracheal intubation, \%26.7of LMA, \%6.7of tracheotomy, and $\% 1.1$ of cricotomy.

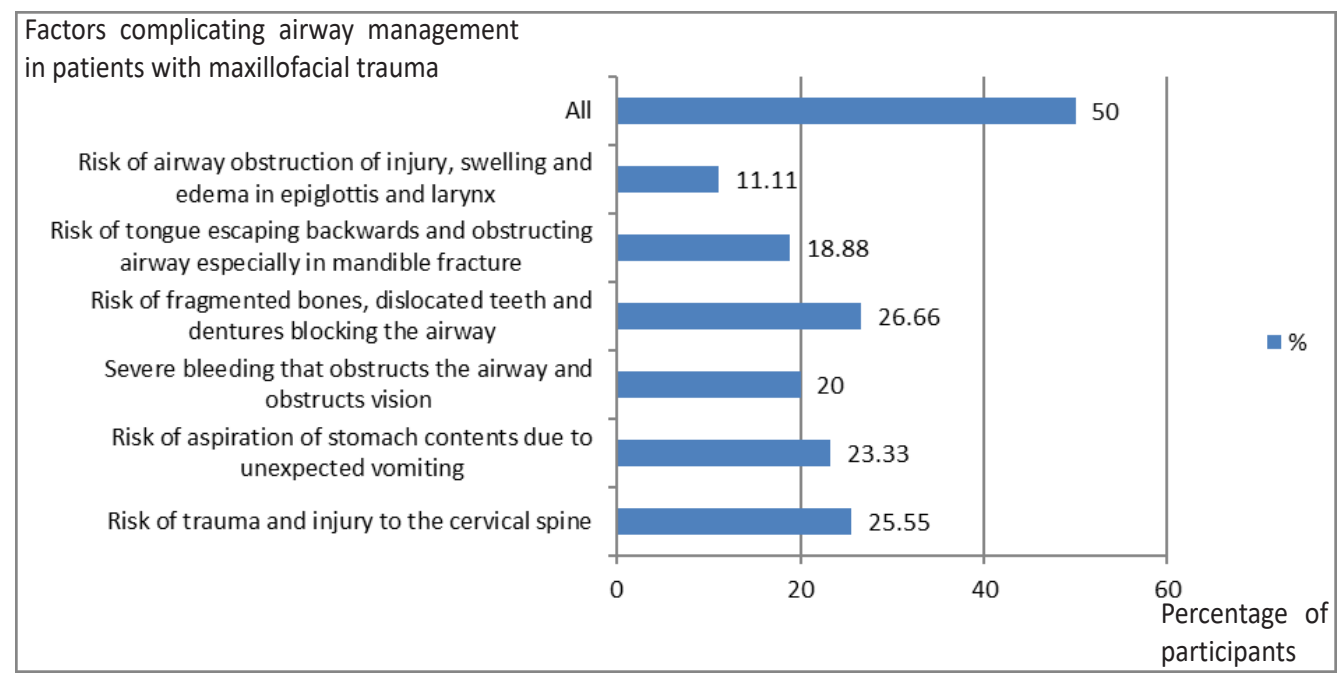

Figure 1. Students' Opinions About Factors complicating airway management in patients with maxillofacial trauma (\%)

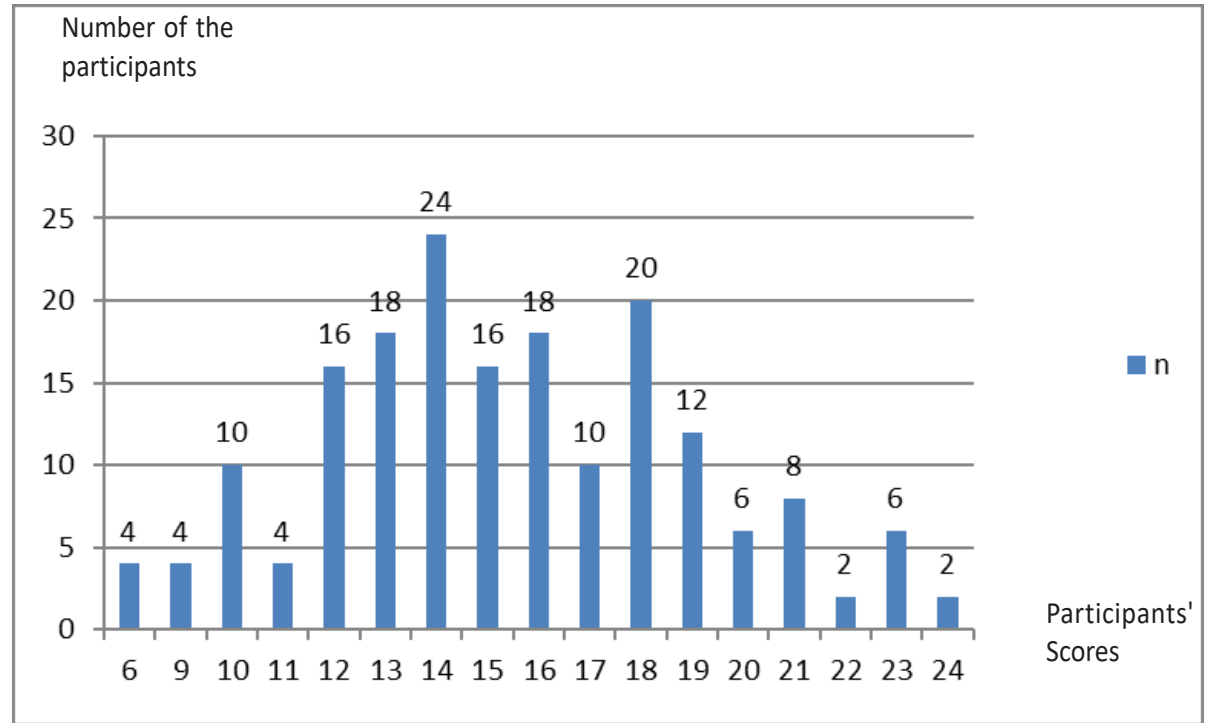

Figure 2. Distribution of Students' Scores on the Questionnaire Scale(n) 
Table 1. The ratio of Correct Answers Given by the Students to the Statements About Airway Management in Patients with Maxillofacial Trauma (\%)

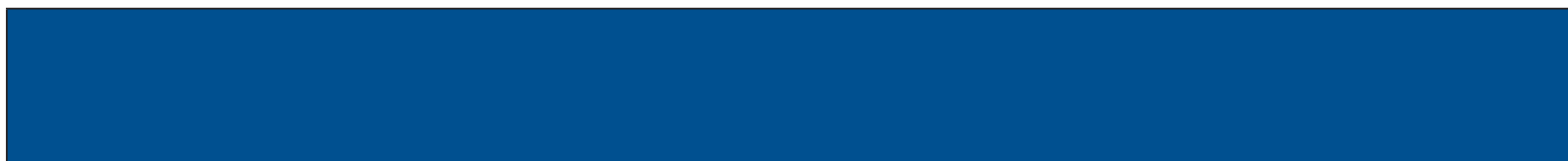

1. It should be assumed that the stomach of the patient with maxillofacial trauma is completely filled.

2. In order to empty the stomach of the traumatic patient, the patient must be vomited.*

3. Alcohol or drug poisoning, brain damage, and pain relieving opioids are potent triggers of nausea and vomiting.

4. Nasogastric catheter is preferred to empty the stomach in patients with broken nose, mid-face or skull base. *

5. The Sellick maneuver is a technique in which the esophagus is blocked by applying pressure on the cricoid cartilage and has been used to reduce the risk of lung aspiration.

6. A patient with a maxillofacial injury should be considered to have a C-spine injury until proven otherwise.

7. In maxillofacial trauma, the patient's C-spine should be protected with a half-neck collar and spinal immobilization in the supine position, and all neck movements should be avoided.

8. Macintosh laryngoscope should be preferred instead of video laryngoscope, if possible, to minimize cervical spine movements during intubation. *

9. If the restricted mouth opening is caused by temporomandibular joint injury, sedation is beneficial in increasing mouth opening. ${ }^{*}$

10. Bleeding in the facial area can go to the oropharynx and trigger vomiting while contributing to the obstruction of the respiratory tract.

11. Intubation is necessary to secure the airway in patients with high risk of pulmonary aspiration.

12. Mask ventilation and intubation can be applied more easily in patients with maxillofacial trauma compared to other traumas. *

13. In maxillofacial injuries, it is necessary to pre-oxygenate the patient with a face mask until airway safety is ensured in order to prevent the patient from entering hypoxia.

14. If preoxygenation cannot be done in any way, the patient should be ventilated by intubation.

15. Endotracheal intubation is the gold standard for airway protection in trauma patients.

16. Fiber optic intubation or video laryngoscope is superior in that it works without being affected by blood, vomit and secretions in the airway of the trauma patient. *

17. Nasoendotracheal intubation should be preferred in patients with skull and skull base fractures, midface and nose fragmented. *

18. Oroendotracheal intubation provides better intraoperative visibility to the surgeon during the operation and allows maxillomandibular fixation. *

19. Failure should be reported after three attempts at tracheal intubation and oxygenation should be performed after unsuccessful intubation.

20. Although supraglottic airway devices are not a final airway device, they are rescue devices for ventilating patients until a definite airway is obtained.

21. Devices such as laryngeal mask airway and combitube are more difficult to administer than intubation, but they provide a more precise and safe airway to the patient.*

22. Tracheotomy takes less time, is easier to apply and causes less complications than cricotomy. *

23. Submental orotracheal intubation has been developed to avoid the need for tracheotomy and to allow unlimited access to the oral area.

24. Cricotomy or tracheotomy is a life-saving procedure in "not intubated, non-ventilable" and selected patients.

25. Extubation should be delayed until normal anatomy is restored and edema subsides.

*:Wrong expression; LMA: Laryngeal mask airway

Table 2. Distribution of Students' Scores According to Their Gender and School Class.

\begin{tabular}{|c|c|c|c|c|}
\hline & $\mathbf{N}$ & Mean & Std. Deviation & Pvalue ${ }^{*}$ \\
\hline \multicolumn{5}{|l|}{ Gender } \\
\hline Male & 86 & 14.79 & 3.322 & \multirow{2}{*}{$0.040^{*}$} \\
\hline Female & 94 & 15.93 & 4.028 & \\
\hline \multicolumn{5}{|l|}{ Class } \\
\hline 5 & 124 & 16.38 & 3.902 & \multirow[b]{2}{*}{$0.000^{* *}$} \\
\hline 6 & 56 & 13.17 & 2.072 & \\
\hline Total & 180 & 15.38 & 3.742 & \\
\hline
\end{tabular}

\#: independent samples t-test significance value; *:p<0.05, **: $p<0.001$ 


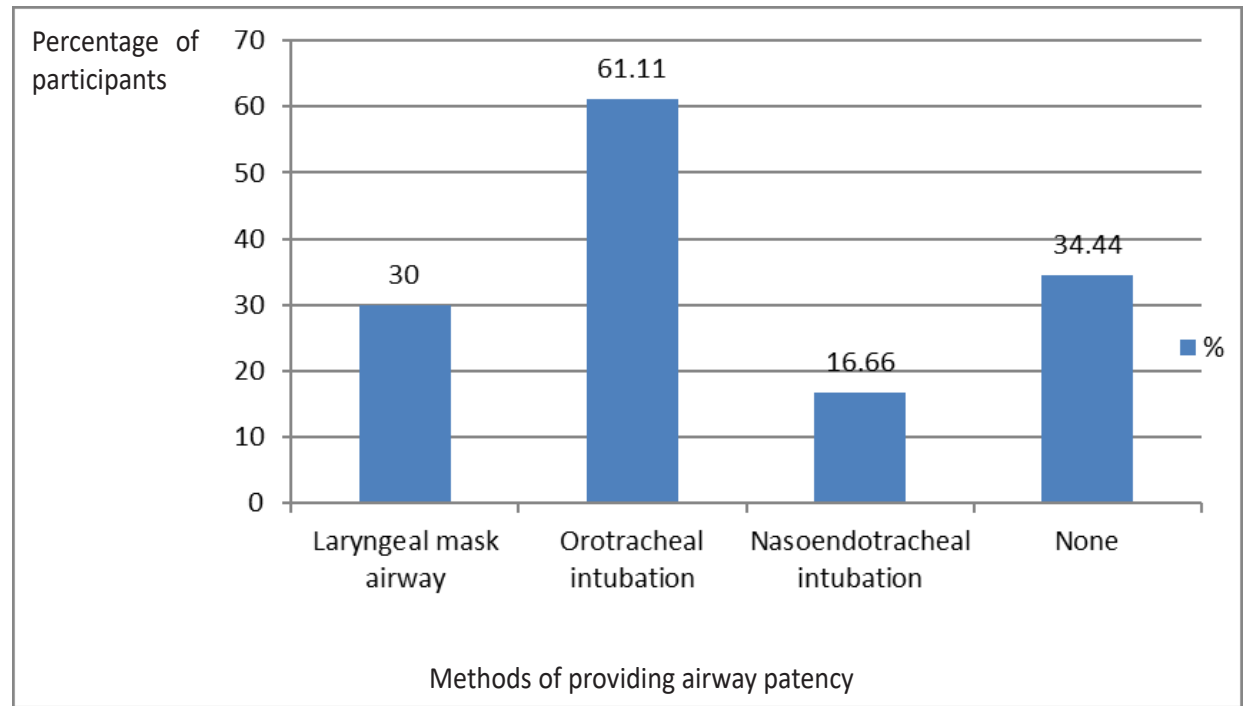

Figure 3. Students' Use of Airway Patency Methods (\%)

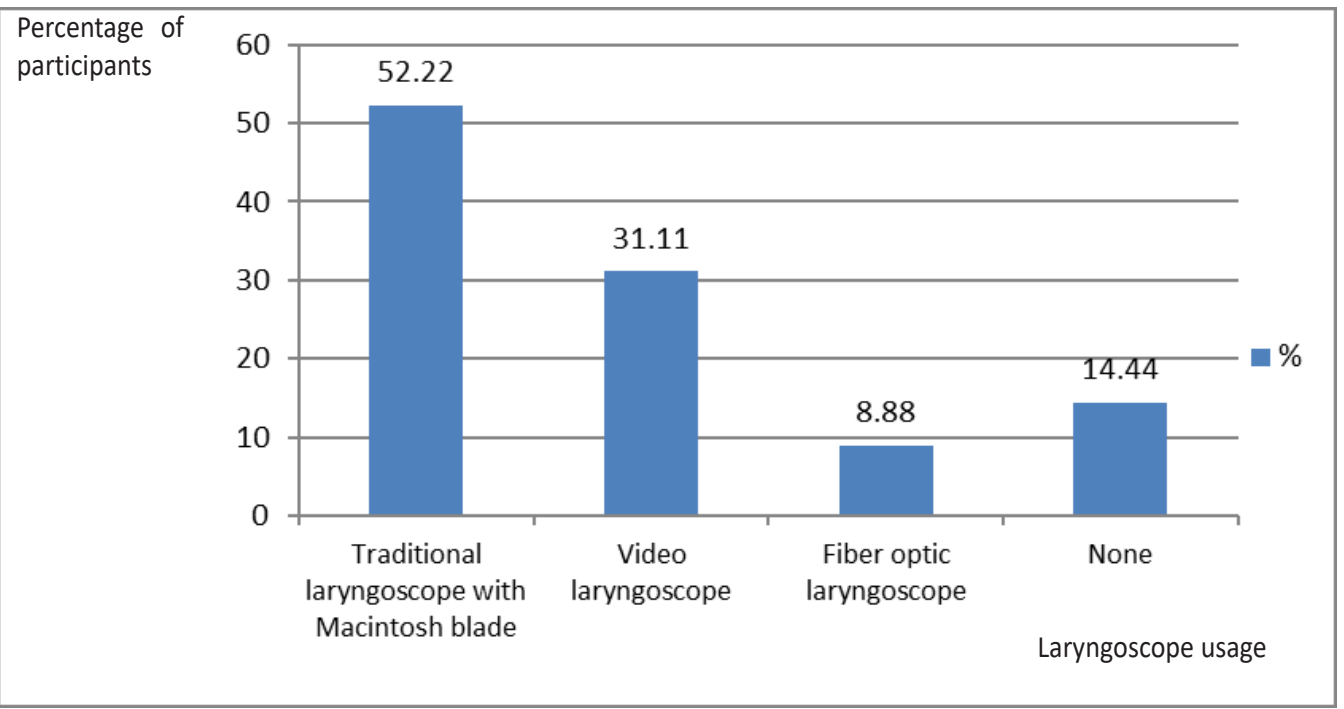

Figure 4. Laryngoscope Usage Status of Students (\%)

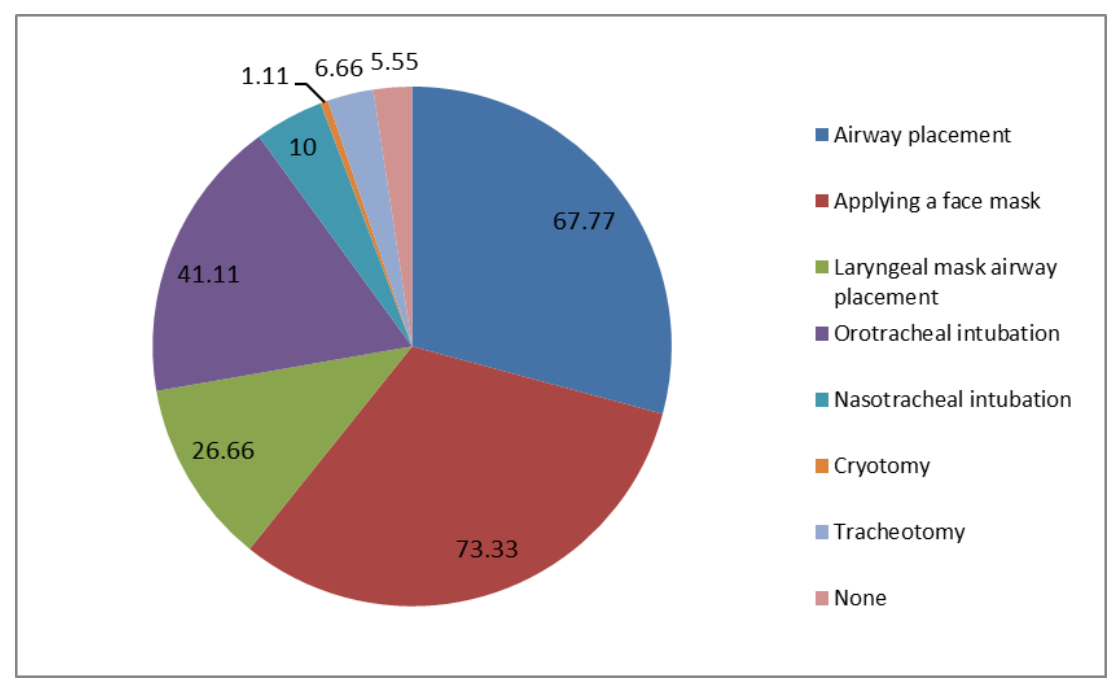

Figure 5. Students' Perception of Themselves as Sufficient in Methods of Providing Airway Patency in Patients with Maxillo-facial Trauma (\%) 


\section{DISCUSSION}

Maxillofacial injuries endanger patients' airways and can potentially be life-threatening. Airway care is the first priority for managing patients with life-threatening injuries, according to ATLS protocol (3). In this study, attention was drawn to the difficulty of airway management in patients with maxillofacial injury and their knowledge and experience of airway management were investigated. In this study, only $16.7 \%$ of the students stated that the first priority in trauma patients was airway management and cervical spine immobilization. Half of the students were aware of all the difficulties in airway management in patients with maxillofacial surgery which in accordance with previousstudy by Hutchinson et al.(2).

Preoxygenation is the first step in the early airway management process and it can prevent the patient from going into hypoxemia. In certain patients, because of the maxillofacial damage itself, preoxygenation is not possible, and hypoxemia may be expected. In trauma patients, endotracheal intubation is the gold standard process for airway safety (1). In the study, $70 \%$ of the students stated that preoxygenation is necessary to prevent the patient from entering hypoxemia until airway safety is ensured, and endotracheal intubation is the gold standard for protecting the airway. More than half $(52.2 \%)$ of the participants in the study think that mask ventilation and intubation are easier in maxillofacial trauma patients compared to other trauma patients. In contrast, there are many challenges for airway management in patients with maxillofacial trauma. The mask cannot be positioned correctly on the face of patients with maxillofacial injuries. A damaged airway can also impede effective air transmission from the mask to the lungs. In a maxillofacial trauma patient, endotracheal intubation is likely to be difficult. During intubation, it may be difficult to see the larynx with a conventional laryngoscope. In a patient with maxillofacial trauma, blood, secretions, and bone fragments may fill the oral cavity, pharynx and larynx (1). In addition, a possible cervical spine injury requires restricted neck movements during intubation. More than half $(52.2 \%)$ of the participants in the study think that mask ventilation and intubation are easier in maxillofacial patients compared to other traumatic patients. In contrast, there are many challenges for airway management in patients with maxillofacial trauma. The ventilation mask cannot be placed well on the face of patients with maxillofacial injuries. Also, an injured airway can block ventilation from the mask to the lungs. Endotracheal intubation will be more difficult in patients with maxillofacial injury. Because it is very difficult to see the vocal cords in these patients with a conventional direct laryngoscope (1). Gupta et al.(11) determined that the majority of patients with maxillofacial trauma had a mouth opening of fewer than two fingers and a Mallampati score of 3 or 4 , and reported that intubation was more difficult in these patients.

Patients with maxillofacial trauma should be considered as "full stomach" as digestion stops when trauma occurs, as in all trauma patients. In addition, the risk of aspiration is high because blood in the upper respiratory tract is swallowed and accumulates in the stomach. It is recommended that the stomach contents be evacuated by a nasogastric tube before improving the patient's breathing. However, the insertion of a nasogastric tube into an uncooperative, sometimes intoxicated patient with a facial injury can trigger vomiting on its own. In addition, it is relatively contraindicated in situations with possible fracture of the skull base (1). In addition, alcohol or drug poisoning, brain injury, and pain-relieving opioids - all common in cases of facial trauma - are potent triggers of nausea and vomiting $(12,13)$. In this study, the majority of the students correctly $(88.8 \%)$ stated that the trauma patient's stomach should be considered as full. However, about half of them $(47.8 \%)$ think that the patient should be vomited to empty the stomach. Vomiting may endanger the patient's life by increasing the risk of aspiration. Similarly, $48.9 \%$ of them had not know the situations in which nasogastric catheter is contraindicated. Sellick's maneuver is a technique in which the esophagus is blocked by applying pressure to the cricoid cartilage and has historically been used to mitigate the risk of lung aspiration (14). This maneuver can result in significant inhibition of endotracheal intubation because the laryngeal appearance has deteriorated (15). Also, its effectiveness in preventing aspiration is doubtful (16), and in some cases can cause a ruptured esophagus. Therefore, the use of cricoid pressure as aspiration prophylaxis in trauma patients is no more shown (17). In this study, $67.8 \%$ of the students answered the question about the Sellick's maneuver correctly.

Cervical spine injuries have been identified in 1-10\% of patients with facial fractures (18). Overall, mid-face injuries are related to $\mathrm{C5}-7$ trauma, while lower facial injuries are often related to C1-4 trauma (19). It is assumed that a patient with a supraclavicular injury has a C-spine injury unless confirmed by imaging otherwise (20). The patient's C-spine should be protected by a half-neck collar and spinal immobilization in the supine position, and all neck movements should be avoided. In this study, the majority of the students $(81.1 \%)$ stated that the possibility of c-spine injury should be considered in patients with maxillofacial trauma, while $77.8 \%$ had information about how to protect the c-spine of the traumatic patient. In some studies, video laryngoscopy was recommended instead of a Macintosh blade to minimize neck movements (21). Using a video laryngoscope may be beneficial for patients who require immobilization of the cervical spine, rather than a traditional laryngoscope with a Macintosh blade (22). If the restriction of the opening of the mouth is caused by a temporo-mandibular joint (TMJ) injury, sedation does not enhance the opening of the mouth and can exacerbate the scenario. The study findings showed that only less than half of the students (41\%) were aware of the superiority of the video laryngoscope in minimizing neck movements. In addition, half of the students (51.1\%) did not have enough knowledge that TMJ injury could limit the mouth opening. 
In patients with major trauma, particularly in trauma involving more than two-thirds of the face, "pan facial trauma", uncontrolled heavy bleeding is possible. Since the head and neck area are plenty vascularized, serious lifethreatening bleeding may emerge (23). Bleeding affects the patient's condition and prognosis in many ways: a) Blood accumulating in the oral cavity may prevent mask ventilation, b) it may also make intubation difficult by preventing the appearance of anatomical structures c) large hemorrhages may endanger the circulation and cause the death of the patient; (d) coagulation may be impaired due to large blood transfusion, and (e) bleeding complicates surgical procedures. Management of the patient involves volume replacement and local control of bleeding $(24,25)$. Hemostasis can be achieved by external direct pressure, sutures, and staples, filling the oral cavities from the inside, balloon pads, and reduction of facial fractures. When conservative treatment failures, intraarterial embolization or surgical ligation of bleeding vessels may be necessary (26). In the study, $75.6 \%$ of the students stated that bleeding in the face area can make airway management difficult. However, it was observed that only $8.8 \%$ of the students were knowledgeabout all hemostasis methods in maxillofacial injuries.

The inability to see the vocal cords of a maxillofacial trauma patient is the major impediment to successful endotracheal intubation. To overcome this hurdle, various airline devices and strategies have been improved. Some instruments, such as the flexible fiberoptic bronchoscope (FOB) and video laryngoscope provide an indirect view of the vocal cords and have been recommended in situations where intubation is difficult (27). However, it is very difficult for these devices to give a good image in a trauma patient due to blood and secretions. In this study, only $27.8 \%$ of the students stated that fiber optic intubation and video laryngoscope may not provide a good vision when affected by the patient's secretions such as blood and vomit.

Supraglottic airway devices (SAD), such as the LMA and combitube, are a crucial device for managing the difficult airway (28). The SAD is blindly put in the oropharynx for airway treatment of the trauma patient and its efficient insertion involves limited experience $(29,30)$. However, SADs does not ensure a precise airway and can be dislocated when the patient with SAD is transported. It is not the last airway device for the maxillofacial trauma patient, however, SAD is a perfect rescue tool to ventilate patients until a precise airway has been accomplished (31). However, combitube use in a patient with maxillofacial trauma may cause additional damage to the upper respiratory tract (32). In this study, it was observed that $54.4 \%$ of the students did not have correct knowledge about devices such as LMA and combitube.

Surgical formation of an airway is a secure procedure of protecting the airway when the operation is performed by a practiced surgeon. However, it includes a $6 \%$ risk of complications such as bleeding or pneumothorax (33). This operation can be hard to perform in an emergency $(34,35)$, and the procedure can sometimes be fatal (36). It can be quite stressful for the operator, particularly for the less experienced person $(37,38)$. In this study, it was revealed that $62.2 \%$ of the students did not know the difference between tracheostomy and cricotomy. Only $34.4 \%$ of the students knew that orotracheal intubation reduced the visibility of the oral cavity during the surgical procedure and made postoperative maxillomandibular fixation impossible. Nasoendotracheal intubation allows maxillomandibular fixation (39) but it is contraindicated in patients with skull fracture or skull base fracture (40). It was revealed that $39.9 \%$ of the students in this study were not aware of this contraindication of nasoendotracheal intubation. Maxillofacial surgeons performed submental and retromolar intubation in selected patients with maxillofacial trauma to avoid tracheostomy (41). Extubation should be delayed in intubated patients with maxillofacial trauma until the edema is resolved. Peterson et al. (42) reported that $12 \%$ of complications occur during extubation and $5 \%$ healing. In the study, it was observed that $70 \%$ of the students had information about submental orotracheal intubation, while $65.6 \%$ had information about the correct extubation time.

Airway assessment of a patient with maxillofacial trauma should be performed as well and as fast as possible. The doctor must choose the most appropriate method to achieve airway management and the patient should be quickly taken to a well-equipped room. In addition to theoretical knowledge, physicians should also have skills in recognizing and applying instruments used in airway management. In this study, approximately $61.1 \%$ of the students stated that they performed orotracheal intubation, while approximately one third (34.4\%) stated that they did not perform any of the LMA, orotracheal and nasoendotracheal intubation. In addition, only $41.1 \%$ of the students stated that they have sufficient education and skills to perform orotracheal intubation. The rate of students seeing themselves as sufficient in relatively easy procedures such as airway placement (67.7\%) and face mask application (73.3\%) is not very high. While $81.1 \%$ of the students stated that they did not intubate at all in a patient with maxillofacial trauma, $74.4 \%$ thought that a patient with maxillofacial trauma did not have the education and skills to perform intubation comfortably. These results reveal that students' knowledge and experience in airway management in emergencies are insufficient.

In the medical school curriculum, airway management education is given in the $5^{\text {th }}$ year in the anesthesia and reanimation course. Training is carried out both theoretically and practically on mannequins. The high average scores of 5th-grade students may be due to the fact that they have just taken this course. In medical education, maxillofacial traumas are narrowly included in emergency traumas within the scope of emergency medicine courses. On the other hand, in dentistry, while maxillofacial traumas are widely included in the 4th grade oral, dental and maxillofacial surgery curriculum, airway management is only theoretically included in the 5th grade first and emergency aid curriculum. Therefore, it is possible that there are some deficiencies 
in medical education about maxillofacial traumas and in dentistry education about emergency airway education. Therefore, overcoming these problems with mutual internship programs and close interdisciplinary cooperation seems to be a possible solution in practice.

In recent years, there have been some studies investigating the knowledge and skill level of doctors on airway management in Turkey. In the survey conducted among 27 doctors working in ambulances of 112 emergency services in Turkey, 60 percent of ambulance physicians stated that their training was insufficient. In addition, it was observed that none of the doctors received a special training on airway management after graduation. This high rate shows that physicians need more training on airway management, which is the indispensable first step of basic life support in the medical education process (43). In another study investigating the airway management experiences of research assistants in medical specialization training in Turkey, more than $80 \%$ of the participants stated that they received training on airway equipment and its use for the first time in the Anesthesiology and Reanimation internship at the medical faculty. While $34.3 \%$ of the participants stated that they did their first endotracheal intubation after graduating from medical school, $13.4 \%$ stated that they never used the airway, which is one of the simplest airway devices(44). In present study, which is the first study conducted among medical students in Turkey, the rate of participants who never used airway devices such as orotracheal intubation was found to be $34.44 \%$, similar to the results of the previous study. In addition, $5.55 \%$ stated that they consider themselves inadequate in all airway management practices, including airway placement. These findings revealed that there is a significant deficiency in airway management in medical school education.

Airway control is a skill that must be acquired not only for emergency physicians and anesthesiologists but also for all physicians and healthcare professionals. Providing education in this field has become a necessity today. Successful airway management is vital in patients with maxillofacial trauma whose clinical condition requires medical urgency. In order for doctors to know and successfully apply the tools and equipment used to ensure airway patency, the medical school curriculum should be reviewed and the deficiencies should be eliminated. In addition, it is essential for doctors to receive training at regular intervals to improve their knowledge and practice skills. New models of medical education should be developed to allow medical students to acquire technical and non-technical knowledge from the early stages of education through case discussions or real situations. It seems imperative that all components responsible for education, especially anesthesia professional associations, come together and update airway management training with competency-based training instead of a traditional program for physicians to receive qualified training.
This study has some limitations. Since the study was conducted in a medical school, the results do not represent the whole country, although similar training methods are used throughout the country. In addition, in the study, theoretical knowledge of airway management and airway tools in maxillofacial trauma were evaluated. Theoretical and practical evaluations should be made together while evaluating students' knowledge and skills on airway management. However, this study is important in that it is the first study that comprehensively evaluates medical students' knowledge about airway management in maxillofacial trauma.

\section{CONCLUSION}

According to the findings of this study, students have a lack of knowledge about airway management in patients with maxillofacial trauma. It was observed that the level of knowledge of the students about the tools and methods used in providing airway patency was quite low. Airway management in trauma patients should be comprehensively addressed in the curriculum of emergency medicine and anesthesia - reanimation courses taught at the medical school. Students should be provided with educational opportunities, tools, and equipment so that they can improve both their theoretical knowledge and practical skills on airway management. In addition, applied courses, workshops and congresses, and symposiums should be organized at the national level on airway management in emergencies and the participation of young doctors should be encouraged. Teamwork between maxillofacial surgeons, anesthetists, and emergency medicine and trauma specialists is essential to manage the patient with maxillofacial trauma.

Conflicts of interest: The author declare no conflict of interest

\section{REFERENCES}

[1] Barak M, Bahouth H, Leiser Y, Abu El-Naaj I. Airway management of the patient with maxillofacial trauma: review of the literature and suggested clinical approach. Biomed Res Int 2015;2015:724032.

[2] Hutchison I, Lawlor M, Skinner D. ABC of major trauma. major maxillofacial injuries. BMJ 1990;301(6752):595-599.

[3] Mohammad A, Branicki F, Abu-Zidan FM. Educational and clinical impact of advanced trauma life support (ATLS) courses: a systematic review. World J Surg 2014;38(2):322-329.

[4] Walls RM. Management of the difficult airway in the trauma patient. Emerg Med Clin North Am 1998;16(1):45-61.

[5] Garcia A. Critical care issues in the early management of severe trauma. Surg Clin North Am 2006;86(6):1359-1387.

[6] Gruen RL, Jurkovich GJ, McIntyre LK, Foy HM, Maier R V. Patterns of errors contributing to trauma mortality: lessons learned from 2594 deaths. Ann Surg 2006;244(3):371-378.

[7] Mort TC. Complications of emergency tracheal intubation: Immediate airway-related consequences: Part II. J Intensive Care Med 2007;22(4):208-215. 
[8] Mechlin MW, Hurford WE. Emergency tracheal intubation: techniques and outcomes. Respir Care 2014;59(6):881-894.

[9] Boylan JF, Kavanagh BP. Emergency airway management: competence versus expertise? Anesthesiology 2008;109(6):945-947.

[10] Walls RM, Brown CA, Bair AE, Pallin DJ. Emergency airway management: a multi-center report of 8937 emergency department intubations. J Emerg Med 2011;41(4):347-354.

[11] Gupta B, Prasad A, Ramchandani S, Singhal M, Mathur P. Facing the airway challenges in maxillofacial trauma: a retrospective review of 288 cases at a level i trauma center. Anesth Essays Res 2015;9(1):44-50.

[12] Perry M, Dancey A, Mireskandari K, Oakley P, Davies S, Cameron M. Emergency care in facial trauma - a maxillofacial and ophthalmic perspective. Injury 2005;36(8):875-896.

[13] Perry M, Morris C. Advanced trauma life support (ATLS) and facial trauma: can one size fit all?. Part 2: ATLS, maxillofacial injuries and airway management dilemmas. Int J Oral Maxillofac Surg 2008;37(4):309-320.

[14] Sellick BA. Cricoid pressure to control regurgitation of stomach contents during induction of anaesthesia. Lancet 1961;2(7199):404-406

[15] Haslam N, Parker L, Duggan JE. Effect of cricoid pressure on the view at laryngoscopy. Anaesthesia 2005;60(1):41-47.

[16] Bhatia N, Bhagat $H$, Sen I. Cricoid pressure: where do we stand? J Anaesthesiol Clin Pharmacol 2014;30(1):3-6.

[17] Beckers SK, Brokmann JC, Rossaint R. Airway and ventilator management in trauma patients. Curr Opin Crit Care 2014;20(6):626-631.

[18] Beirne JC, Butler PE, Brady FA. Cervical spine injuries in patients with facial fractures: a 1-year prospective study. Int J Oral Maxillofac Surg 1995;24(1):26-29.

[19] Lynham AJ, Hirst JP, Cosson JA, Chapman PJ, McEniery P. Emergency department management of maxillofacial trauma. Emerg Med Australas 2004;16(1):7-12.

[20] Jamal BT, Diecidue R, Qutub A, Cohen M. The Pattern of combined maxillofacial and cervical spine fractures. J Oral Maxillofac Surg 2009;67(3):559-562.

[21] Robitaille A, Williams SR, Tremblay MH, Guilbert F, Thériault $M$, Drolet $P$. Cervical spine motion during tracheal intubation with manual in-line stabilization: direct laryngoscopy versus glideScope ${ }^{\circledR}$ videolaryngoscopy. Anesth Analg 2008;106(3):935-941.

[22] Kill C, Risse J, Wallot $P$, Seidl $P$, Steinfeldt T, Wulf $H$. Videolaryngoscopy with glidescope reduces cervical spine movement in patients with unsecured cervical spine. J Emerg Med 2013;44(4):750-756.

[23] Harris T, Rice S, Watts B, Davies G. The emergency control of traumatic maxillofacial haemorrhage. Eur J Emerg Med 2010;17(4):230-233.

[24] Khanna S, Dagum AB. A critical review of the literature and an evidence-based approach for life-threatening hemorrhage in maxillofacial surgery. Ann Plast Surg 2012;69(4):474-878.

[25] Liu WH, Chen YH, Hsieh CT, Lin EY, Chung TT, Ju DT. Transarterial embolization in the management of life-threatening hemorrhage after maxillofacial trauma: a case report and review of literature. Am J Emerg Med 2008;26(4):516.e3-516. e5.

[26] Cogbill TH, Cothren CC, Ahearn MK, et al. Management of maxillofacial injuries with severe oronasal hemorrhage: a multicenter perspective. J Trauma - Inj Infect Crit Care 2008;65(5):994-999.

[27] Aziz MF, Healy D, Kheterpal S, Fu RF, Dillman D, Brambrink AM. Routine clinical practice effectiveness of the glidescope in difficult airway management: an analysis of 2,004 glidescope intubations, complications, and failures from two institutions. Anesthesiology 2011;114(1):34-41.

[28] Apfelbaum JL, Hagberg CA, Caplan RA, et al. Practice guidelines for management of the difficult airway: an updated report by the american society of anesthesiologists task force on management of the difficult airway. Anesthesiology 2013;118(2):251-270.

[29] Goliasch G, Ruetzler A, Fischer H, Frass M, Sessler DI, Ruetzler $\mathrm{K}$. Evaluation of advanced airway management in absolutely inexperienced hands: a randomized manikin trial. Eur J Emerg Med 2013;20(5):310-314.

[30] Ruetzler K, Roessler B, Potura L, et al. Performance and skill retention of intubation by paramedics using seven different airway devices-a manikin study. Resuscitation 2011;82(5):593597.

[31] Grier G, Bredmose P, Davies G, Lockey D. Introduction and use of the proseal ${ }^{\mathrm{TM}}$ laryngeal mask airway as a rescue device in a pre-hospital trauma anaesthesia algorithm. Resuscitation 2009;80(1):138-141.

[32] Vézina MC, Trépanier CA, Nicole PC, Lessard MR. Complications associated with the esophageal-tracheal combitude ${ }^{\circledR}$ in the pre-hospital setting. Can J Anesth 2007;54(2):124-128.

[33] Kearney PA, Griffen MM, Ochoa JB, Boulanger BR, Tseui BJ, Mentzer RM. A single-center 8-year experience with percutaneous dilational tracheostomy. Ann Surg 2000;231(5):701-709.

[34] Altman KW, Waltonen JD, Kern RC. Urgent surgical airway intervention: a 3 year county hospital experience. Laryngoscope 2005;115(12):2101-2104.

[35] Yuen HW, Loy AHC, Johari S. Urgent awake tracheotomy for impending airway obstruction. Otolaryngol - Head Neck Surg 2007;136(5):838-842.

[36] Gupta P, Modrykamien A. Fatal case of tension pneumothorax and subcutaneous emphysema after open surgical tracheostomy. J Intensive Care Med 2014;29(5):298301.

[37] Greenland KB, Acott C, Segal R, Goulding G, Riley RH, Merry AF. Emergency surgical airway in life-threatening acute airway emergencies - why are we so reluctant to do it? Anaesth Intensive Care 2011;39(4):578-584.

[38] Cooper S. We need to cut the neck!: confronting psychological and moral distress during emergency cricothyrotomy. Narrat Inq Bioeth 2013;3(2):E5-E9.

[39] Hall CEJ, Shutt LE. Nasotracheal intubation for head and neck surgery. Anaesthesia 2003;58(3):249-256.

[40] Muzzi DA, Losasso TJ, Cucchiara RF. Complication from a nasopharyngeal airway in a patient with a basilar skull fracture. Anesthesiology 1991;74(2):366-368.

[41] Robertson CG, Doucet JC. Helping anesthesiologists understand facial fractures. Oral Maxillofac Surg Clin North Am 2013;25(4):561-572.

[42] Peterson GN, Domino KB, Caplan RA, Posner KL, Lee LA, Cheney FW. Management of the difficult airway: a closed claims analysis. Anesthesiology 2005;103(1):33-39. 
[43] Kuş A, Gürkan Y, Solak M, Toker K. Assesment of the prehospital airway management from the view of equipment and the practitioners. Turkiye Klinikleri J Anest Reanim 2011;9(2):84-89.

[44] Hacıbeyoğlu G, Arıcan Ş, Tuncer Uzun S, Tavlan A. Evaluation of the contribution of anesthesiology and reanimation job rotation and internship to the residents' experiences of airway management in medical and surgical specialties. Tıp Eğitimi Dünyası 2019;18(56):30-44.

How to cite this article: Ekici O. Knowledge Levels of Medical Students Related to Airway Management in Patients with Maxillofacial Trauma. Clin Exp Health Sci 2021; 11: 620-629. DOI: 10.33808/ clinexphealthsci.890212 